\title{
Empirical and CFD analysis of silica nanofluid using a double pipe heat exchanger
}

\author{
G. Nivedini ${ }^{1} \cdot$ Kalapala Prasad $^{1} \cdot$ Ch. Sandeep ${ }^{2} \cdot$ K. Venkateswara Rao ${ }^{3}$
}

Received: 11 September 2020 / Accepted: 18 November 2020 / Published online: 4 December 2020

(c) Springer Nature Switzerland AG 2020

\begin{abstract}
The heat exchangers are widely used in the industrial processes to either heat or cool the working fluids. They prevent the utilization of an external heat source, which highly reduces the cost of production. The Heat exchangers having high thermal conductivity are required to meet the expanding industrial needs. This study targets the enhancement of thermal energy transfer by the usage of nanofluid instead of the conventional fluid such as water, in the concentric tube heat exchanger. The nanofluid was prepared by the usage of silica nanoparticles, having distilled water as the primary fluid. The silica nanoparticles synthesized by green synthesis method are conformed by X-ray Diffraction, zeta potential, FESEM techniques. The hot liquid in the heat exchanger remains unchanged while, the conventional fluid is replaced by the prepared silica nanofluid as cold fluid. In this research, a double pipe heat exchanger is modeled and meshed using ANSYS Fluent 14.5. The heat transmission attributes of silica nanofluid in the equipment are analyzed with the help of fluent software. The amount of nanofluid used for the entire experiment was about $5 \mathrm{I}$ and in order to get a $0.05 \%$ volume concentration approximately $7 \mathrm{~g}$ of nanoparticles were used. The results of Computational Fluid Dynamic (CFD) analysis and the experimentation were compared and justified. In CFD analysis the cold and hot outlet temperatures are 313.18 and $354.03 \mathrm{~K}$ respectively, while the experimental results are 322 and $346 \mathrm{~K}$ respectively. An improvement of $10^{\circ} \mathrm{C}$ was found in the cooling of the heat exchanger upon the usage of silica nanofluid. The outcome of the present research work, reveals that the addition of nanoparticles to the host fluid leads to significant improvement of thermal properties.
\end{abstract}

Keywords Silica nanoparticles · Double pipe heat exchanger · Nanofluid · CFD analysis

$\begin{array}{ll}\text { Nomenclature } \\ \mathrm{mm} & \text { Millimeter } \\ \mathrm{V}_{\mathrm{f}} & \text { Volume fraction } \\ \mathrm{W}_{\mathrm{m}} & \text { Weight of nanoparticle } \\ \rho_{\mathrm{m}} & \text { Density of nanoparticle } \\ \mathrm{kg} & \text { kilograms } \\ \mathrm{s} & \text { Second } \\ \mathrm{K} & \text { Kelvin } \\ \mathrm{k} & \text { Thermal conductivity } \\ \mathrm{J} & \text { Joule } \\ \mathrm{nm} & \text { nano meter } \\ \mathrm{T}_{\mathrm{hi}} & \text { Hot inlet temperature }\end{array}$

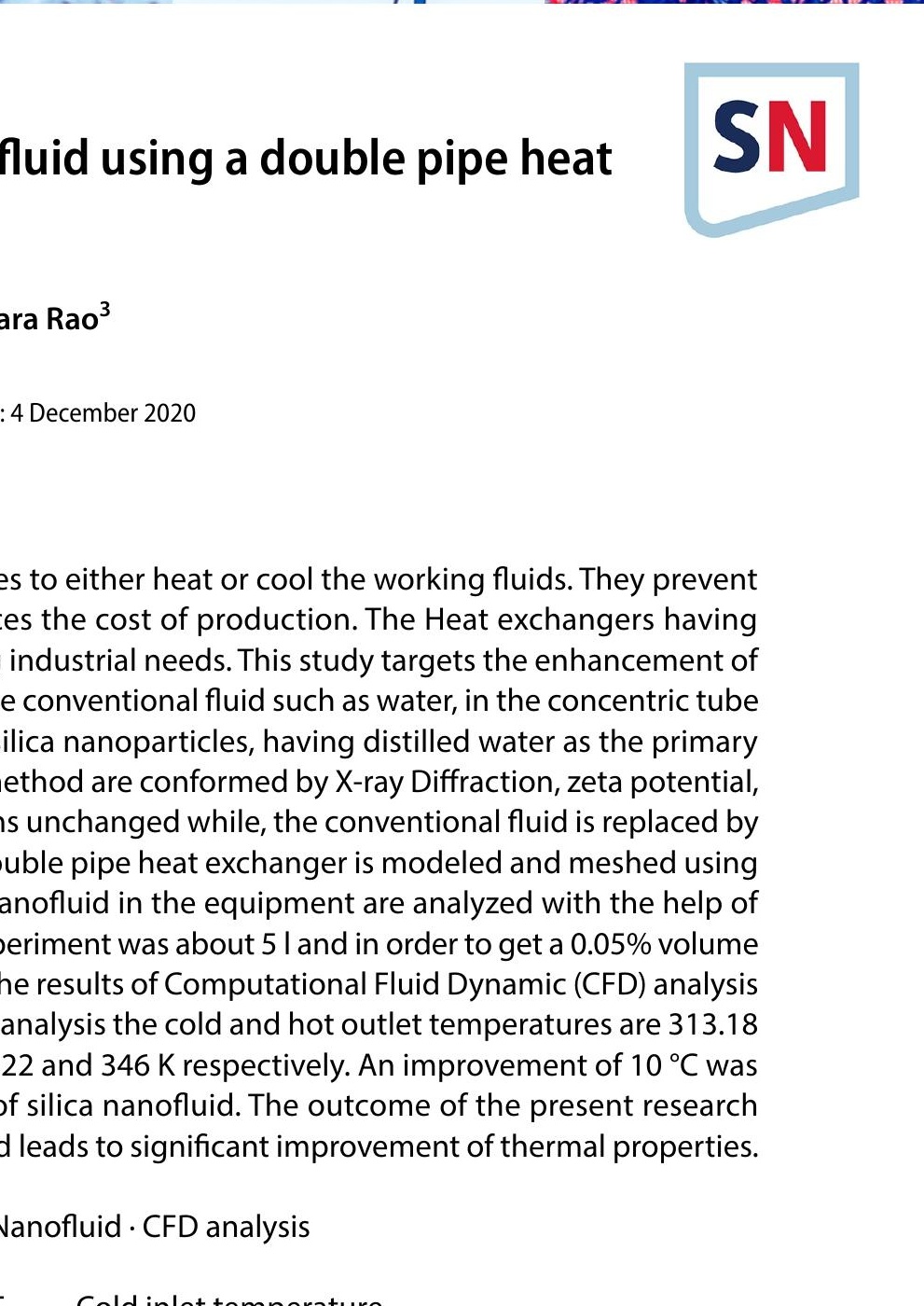

$\mathrm{T}_{\mathrm{ci}} \quad$ Cold inlet temperature

$\%$ Percentage

$\varepsilon \quad$ Rate of dissipation of energy

ph Potential of hydrogen

$\mathrm{W}_{\mathrm{f}} \quad$ Weight of nanofluid

$\rho_{f} \quad$ Density of nanofluid

g grams

W Watts

m meter

$\rho \quad$ DENSITY

$\mathrm{Cp}$ Specific heat

$\mathrm{au}$ astronomical unit

K. Venkateswara Rao, kalagadda2003@jntuh.ac.in | ${ }^{1}$ Mechanical Department, JNT University, Kakinada, Andhra Pradesh 533003, India. ${ }^{2}$ Mechanical Department, Institute of Aeronautical Engineering, Dundigal 500043, India. ${ }^{3}$ Center for Nanoscience and Technology, Institute of Science and Technology, JNT University, Hyderabad, Telangana 500085, India. 


\section{$\mathrm{mV} \quad$ Milli volts \\ $\mathrm{T}_{\text {ho }} \quad$ Hot outlet temperature \\ $\mathrm{T}_{\mathrm{co}} \quad$ Cold outlet temperature \\ ${ }^{\circ} \mathrm{C}$ Degree centigrade \\ k Turbulent energy}

\section{Introduction}

The industrial sector mainly functions on the usage of thermal energy for their heating and cooling systems. The transmission of heat energy from one channel to another can be done by using a heat exchanger. The medium can be either gas or fluid. The growing industrial demands require a good heat transmission system. For this reason many researches were conducted and in the year 1995, a new fluid was formulated by Choi [1]; in which nano sized flecks were scattered in a host fluid and these liquids were termed as nanofluids. R. L. Hamilton and O. K. Crosser [2]; study introduced the usage of nanofluids to improve the heat transfer properties of fluids. This led to a new field of research which helped to deal with the rapidly increasing industrial demands. Many research works have been conducted using different nanofluids which are synthesized using various nanoparticles $\left(\mathrm{SiO}_{2}, \mathrm{Al}_{2} \mathrm{O}_{3}, \mathrm{Ag}, \mathrm{Cu}, \mathrm{CuO}, \mathrm{CeO}_{2}\right.$, $\mathrm{MgO}, \mathrm{Fe}_{2} \mathrm{O}_{3}, \mathrm{NiO}$, Graphene, CNTs, etc.) [3-9] and base fluid materials (water, EG, PEG, etc.).

Researchers Pak and Choi [10], experimentally researched the thermal properties of nanofluid with oxides of both aluminum and titanium as nano particles in the horizontal tube under uneven flow and stable heat flux. It was reported that particles wiQ1th high conductivity and size are required to improve heat transfer properties. Under the counter flow state, the heat transmission and motion dynamics of titanium oxide nanofluid, having water as the base liquid was experimentally investigated by Duangthongsuk and Wongwises 2009 [11] for horizontal pipe heat exchanger. Their study reported that the inclusion of nano sized flecks to the main fluid resulted in the increment of conductivity and viscosity of nanofluids. The researches [12-18] state that nano fluids have huge advantages like longer stability, low pressure drop and showed an evident increase in the thermal efficiency of the equipment in comparision to the regular fluids.

Khedkar et al. 2012 [19], has researched water and ethylene glycol based fluids having copper oxide nano-sized particles. The final output indicates an increase of $23 \%$ in heat transfer for $0.3 \%$ concentration. In the study done by Xie et al. 2011 [20], the result state the increment of thermal characteristics by $86 \%$ with the usage of ethylene glycol based nanofluids with $5 \%$ graphene in comparison to the host fluid. Harris et al. 2006 [21], experimented using $\mathrm{Al}_{2} \mathrm{O}_{3}$ and $\mathrm{CuO}$ nanofluids in laminar or turbulent flow at different boundary conditions. The results indicated that the $\mathrm{Al}_{2} \mathrm{O}_{3}$ nanofluids show more enhancement compared with $\mathrm{CuO}$. His study also indicates that heat transfer enhancement by nanofluid depends on factors like increment of thermal conductivity, nanoparticles chaotic movements, fluctuations and interactions. Sharma et al. 2010 [22]; stated that thermal property alter with the change in concentration, i.e., for silver nanofluids with Ethylene Glycol as primary fluid, conductivity increases with increment in ppm of silver.

The study of fluid interactions with another fluid, solid, or gas by the usage of numerical solutions is known as Computational Fluid Dynamic (CFD) analysis. In the CFD analysis, solvers convert the partial differential equations to algebraic equations to solve the equations efficiently. Pendyala et al. [23], in 2015, stated that CFD is a very good medium for learning the thermal and motion properties of liquids in intricate shaped equipment. The CFD investigation done by Ashok et al. [24] in the year 2013, on parallel and counter flow heat exchangers using different nano fluids states that as the cooling water flow increased, so did the amount of heat transfer. With the help of different nanoparticles like $\mathrm{SiO}_{2}, \mathrm{Al}_{2} \mathrm{O}_{3}$ and $\mathrm{CuO}$, the forced heat transmission characteristics of fluids are numerically analyzed using a 3D car model, by A. Kamyar et al. [25]. The results obtained indicate that $\mathrm{Cu}$ and $\mathrm{Al}$ based nanofluids exhibit high thermal properties in comparison to silica nanofluids.

The aim of the present work was to improve the amount of heat transmitted in the double pipe heat exchanger by using silica nanofluid. The silica nano particles were prepared from bamboo leaves by the usage of green synthesis method. The output temperatures of both the cold fluid and hot fluid when nano fluid was used were compared to the usage of distilled water as cold fluid. The validation was done by the usage of CFD analysis for the double pipe heat exchanger using the same specifications and boundary conditions.

\section{Experimentation}

In the double pipe heat exchanger the nano fluid flows through the inner pipe and the water flows through the outer pipe in counter flow direction resulting in the transfer of heat between the two fluids without any direct contact between them. Bamboo leaves are collected for the synthesis of silica nanoparticles and then the silica nanofluid is prepared. The coolant used in the heat exchanger is a liquid. The CFD analysis is also done using the properties of the synthesized silica nanofluid. Few assumptions are made at the beginning of heat exchanger analysis. The loss 
of energy to the circumambience, by the coolant or at the $\mathrm{U}$ shaped bends of the pipes is negligible.

\subsection{Equipment specifications}

The parameters of the experimental apparatus (Fig. 1) are mentioned in Table 1. The outer tube consists of the cold liquid, while the inner tube has hot liquid passing through it. The cold fluid tube, i.e. the outer tube is of galvanized iron. The hot fluid tube is made of copper. The inner pipe should be of a material having high thermal resistance, as the thermal reading of the hot fluid can reach up to $100^{\circ} \mathrm{C}$. The span of the heat exchanger is nearly $1200 \mathrm{~mm}$.

\subsection{Synthesis of silica nanoparticles}

The silica nanoparticles are prepared through a green synthesis method by using bamboo leaves. Rangaraj et al. 2017 [26] study states the synthesis process of silica nanoparticles. Firstly, the bamboo leaves were cleansed to remove the dust. Later, the dried leaves are powdered and heated in the furnace at $1023 \mathrm{~K}$ for $3 \mathrm{~h}$ to obtain ash known as bamboo leaf ash. $6 \mathrm{~N}$ Hydrochloric acid solution was used for the treatment of ash under continuous stirring at $343 \mathrm{~K}$ for $1 \frac{1 / 2}{h}$ to eradicate the pollutants. The ash acquired was next washed with the help of distilled water until the $\mathrm{pH}$ is 7 . Under stirring, $2.5 \mathrm{~N} \mathrm{NaOH}$ was added for $2 \mathrm{~h}$ at $353 \mathrm{~K}$ to get silicate from the ash. Until the $\mathrm{pH}$ reaches 2.5 , the dropwise addition of sulphuric acid to the supernatant obtained, consists of sodium silicate, was done. The solution then turned transparent. The silica precipitate was rinsed with water to eliminate sodium components. Oven is used to dry the powder attained at $333 \mathrm{~K}$
Table 1 Specifications of heat exchanger

\begin{tabular}{lll}
\hline Specifications & Inner pipe $(\mathrm{mm})$ & Outer pipe $(\mathrm{mm})$ \\
\hline Material & Copper & Galvanized iron \\
Length & 1200 & 1200 \\
Inner diameter & 10.5 & 21 \\
Outer diameter & 12.5 & 25 \\
\hline
\end{tabular}

for almost 2 days. After $2 \mathrm{~h}$ of calcinations at $723 \mathrm{~K}$, the required silica powder was collected.

\subsection{Silica nanofluid preparation}

The nanofluid was produced by a two-step approach. The prepared silica nanoparticles were dispersed in distilled water, which acts as the primary fluid. The preparation of nanofluids doesn't just involve the addition of nano sized flecks in the host fluid, but must also ensure long lasting dispersion with no chemical disparity of fluid or the nanoparticles. A sonicator or high shear blending device is used to mix nano-powders with base fluids. Regular usage of sonication is needed to reduce particle cluster formation.

$V_{f}=\frac{\frac{w_{f}}{\rho_{f}}}{\frac{w_{f}}{\rho_{f}}+\frac{w_{m}}{\rho_{m}}}$

The amount of nanoparticles added depends upon the concentration of the nanofluid required. Nanofluid was prepared with the desired concentration using Eq. (1) [27]. For, preparation of $0.05 \%$ volume concentration of silica nanofluid, $1.325 \mathrm{~g}$ of silica nanoparticles prepared was added to the base fluid. Distilled water was taken as

Fig. 1 Experimental apparatus

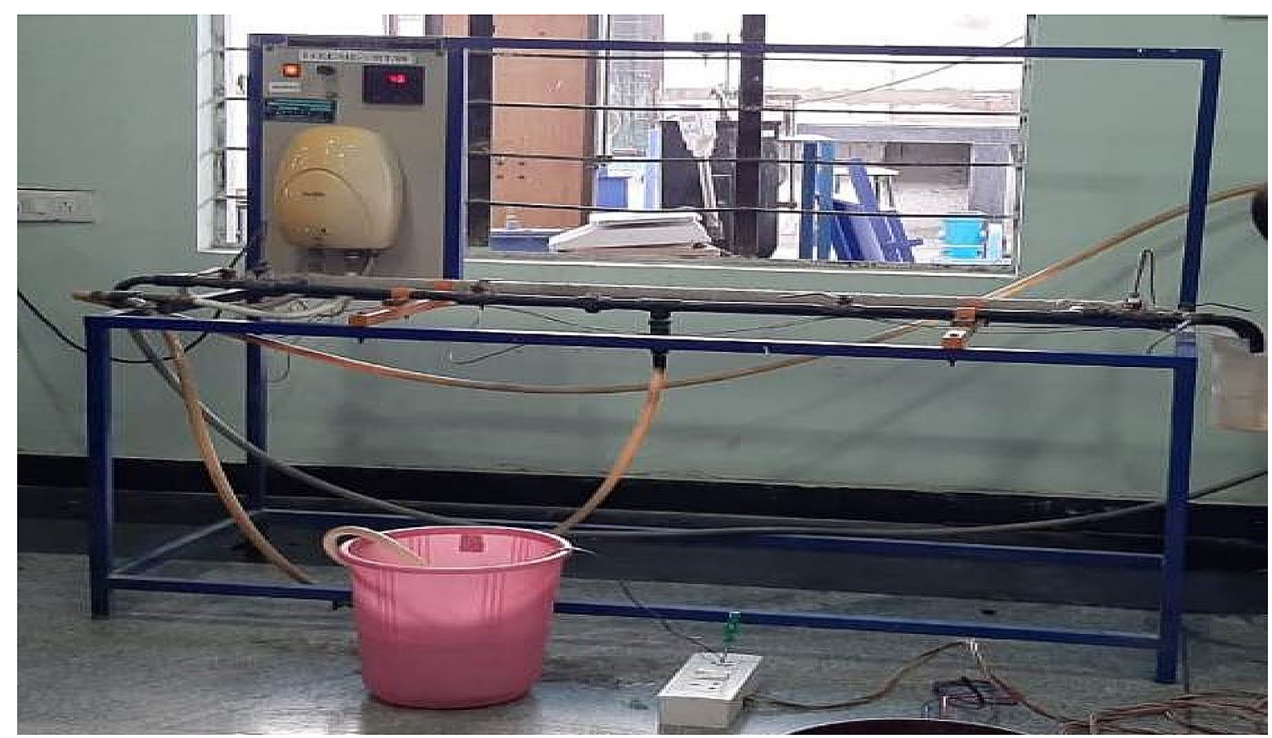




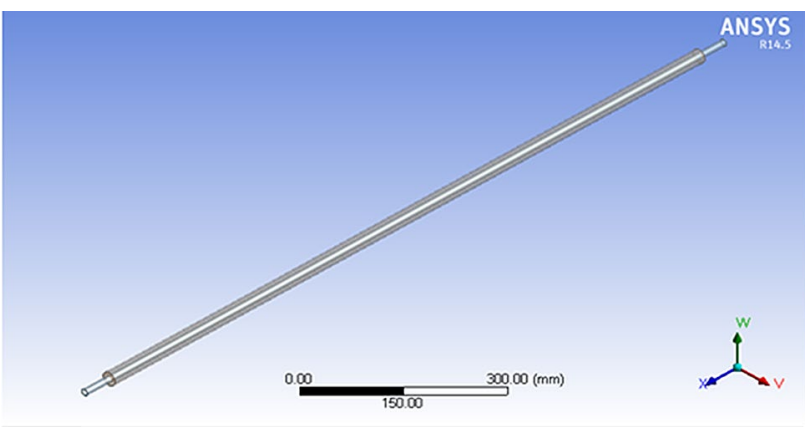

Fig. 2 Geometry of experimental apparatus

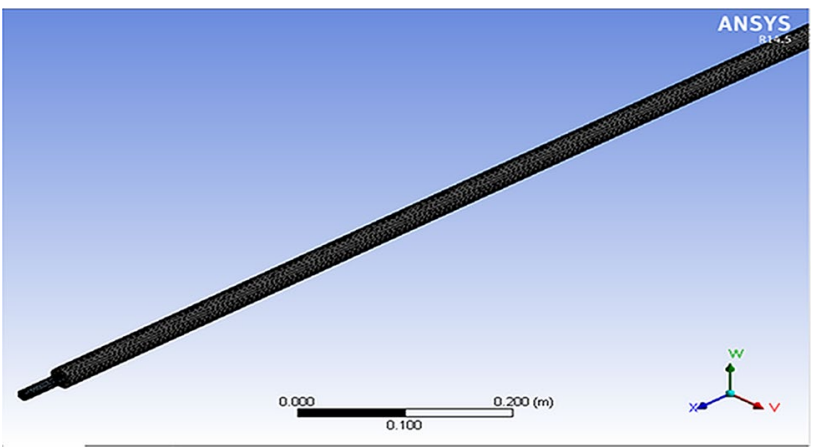

Fig. 3 Meshing of experimental apparatus

a primary liquid. Firstly, the nano sized fragments of silica were measured using the digital weighing machine. Then, they were added to the base liquid in a glass beaker and sonicated using Probe sonicator for 3-4 h. After sonication, a stable nanofluid was obtained.

\subsection{CFD analysis of heat exchanger}

The CFD analysis has three main phases. In pre-processing, the problem statement is converted to a computer model. Mesh generation and setting the boundary conditions are also done in this phase. The actual computation is done in the solving phase with the help of a solver. Finally, the results obtained are analyzed in the post-processing phase. The modeling of the heat exchanger is done using ANSYS software. The outer pipe consists of silica nanofluid, which acts as the cold fluid. While the inner pipe contains water, which acts as a hot fluid. After modeling the heat exchanger, the meshing process such as face mesh, edge meshing, inflation, etc., are applied. The mesh generated is a polyhedron mesh consisting of 473,012 nodes and $1,287,109$ elements. The geometry and meshing of the experimental apparatus are shown in Figs. 2 and 3.

In the CFD analysis, the properties of materials that may be solids, fluids, or gases used need to be specified. Here,
Table 2 Solid properties

\begin{tabular}{llll}
\hline Solid properties & $\begin{array}{l}\text { Density }(\rho) \\
\left(\mathrm{kg} / \mathrm{m}^{3}\right)\end{array}$ & $\begin{array}{l}\text { Thermal conduc- } \\
\text { tivity }(\mathrm{K})(\mathrm{W} / \mathrm{m} \mathrm{K})\end{array}$ & $\begin{array}{l}\text { Specific heat } \\
(\mathrm{Cp})(\mathrm{J} / \mathrm{kg} \mathrm{K})\end{array}$ \\
\hline Copper & 8980 & 387.5 & 380 \\
Iron & 7850 & 344.8 & 460.54 \\
\hline
\end{tabular}

Table 3 Fluid properties

\begin{tabular}{llll}
\hline Fluid properties & $\begin{array}{l}\text { Density }(\rho) \\
\left(\mathrm{kg} / \mathrm{m}^{3}\right)\end{array}$ & $\begin{array}{l}\text { Thermal conduc- } \\
\text { tivity }(\mathrm{K})(\mathrm{W} / \mathrm{m} \mathrm{K})\end{array}$ & $\begin{array}{l}\text { Specific heat } \\
(\mathrm{Cp})(\mathrm{J} / \mathrm{kg} \mathrm{K})\end{array}$ \\
\hline Silica nanofluid & 1014 & 0.63 & 4105.29 \\
Water & 1000 & 0.59 & 4179.6 \\
\hline
\end{tabular}

the inner tube material is copper and that of the outer tube is iron. Similarly, the fluids used are water and silica nanofluid. The mass flow rates are also to be specified. For silica nanofluid, the mass flow rate is $0.133 \mathrm{~kg} / \mathrm{s}$ and for water, $0.027 \mathrm{~kg} / \mathrm{s}$. The properties of solids are mentioned in Table 2, while the properties of fluids are in Table 3.

\section{Results and discussion}

\subsection{XRD}

The XRD analysis in Fig. 4, confirms the generation of silica nano sized particles from bamboo leaves. The XRD pattern of these nanoparticles designates a characteristic amorphous nature of solids, indicating the lack of crystalline structure. The peak (101) at the position of $22^{\circ}$ confirms that silica is amorphous in nature.

\subsection{FESEM}

The FESEM images of the pure $\mathrm{SiO}_{2}$ nanoparticles synthesized from bamboo leaves have been shown in Fig. 5a, b with resolution $200 \mathrm{~nm}$ and $100 \mathrm{~nm}$ respectively. The formation of silica nanoparticles occurs approximately at range $60-250 \mathrm{~nm}$ width. They have long rod-like shape and are amorphous in nature.

\subsection{Zeta potential}

The difference of the potential value of the base fluid and a fluid layer containing ions related to the dispersed particles in the main fluid is known as zeta potential. The potential value obtained for the silica nanofluid in the study is $-32.7 \mathrm{mV}$, which implies the longer stability of silica nanofluid. 
Fig. 4 X-Ray diffraction pattern of silica nano-particles

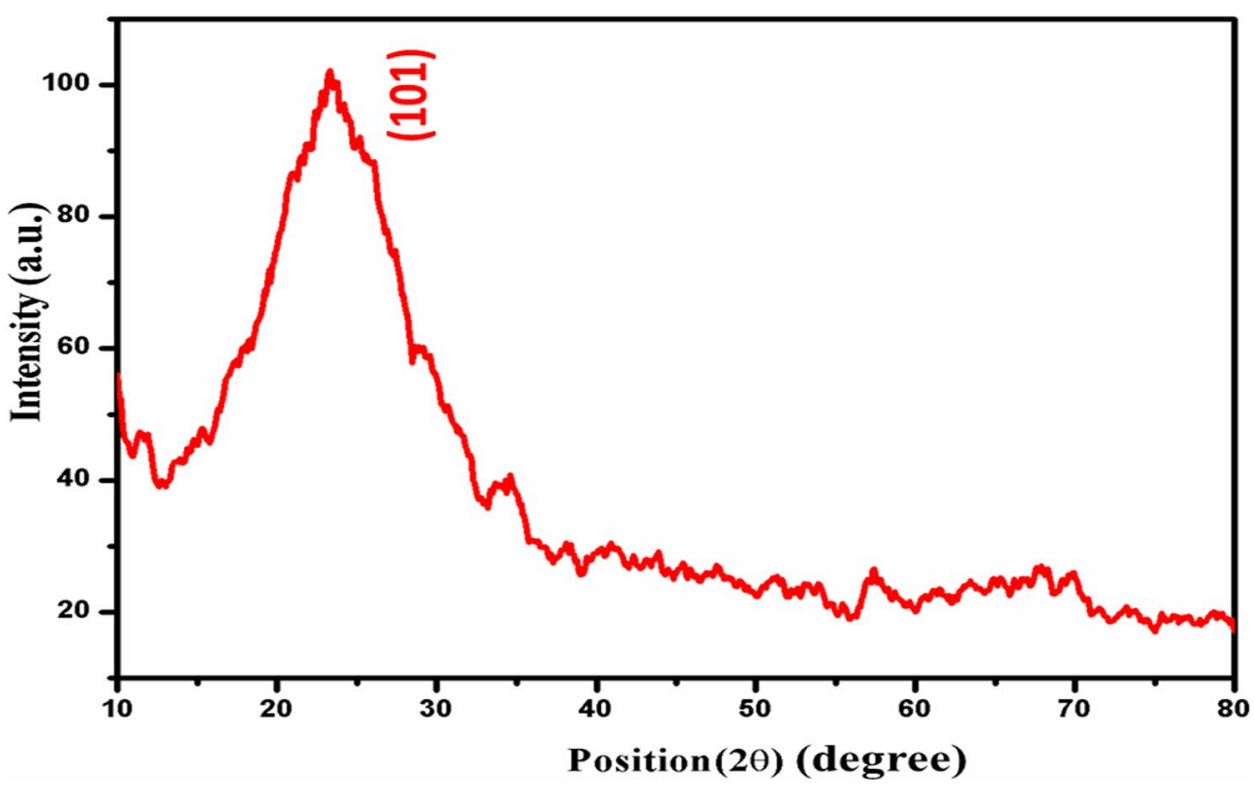

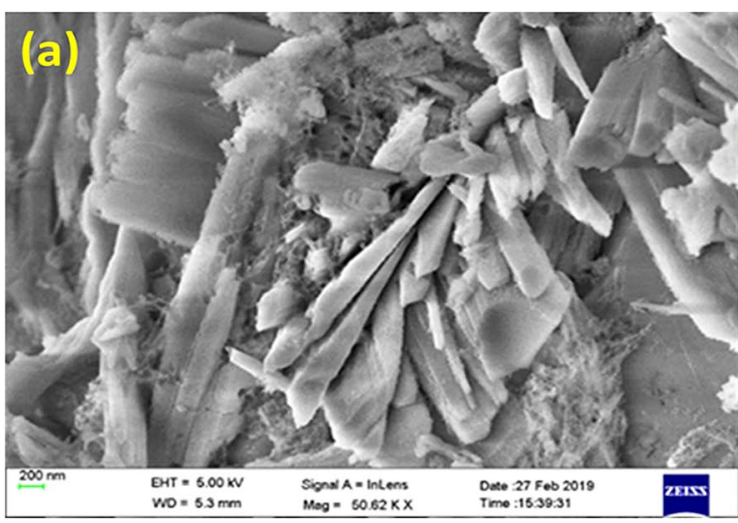

Fig. 5 FESEM images of silica nanoparticles

\subsection{Experimental and CFD results}

The output temperatures of cold fluid and hot fluid are measured using thermocouples. Different outlet temperatures are obtained when water and nanofluid are used as the cold fluid and the experimental investigation were shown in (Fig. 6). The experimental output is mentioned in Table 4.

The cold and hot outlet temperatures when nanofluid is used are $49^{\circ} \mathrm{C}$ and $73^{\circ} \mathrm{C}$ respectively. The above results give the heat gradient for the inner pipe as $9^{\circ} \mathrm{C}$ for water and $21^{\circ} \mathrm{C}$ for silica nanofluid. Similarly, for the outer pipe, it is $13^{\circ} \mathrm{C}$ for nanofluid and $4{ }^{\circ} \mathrm{C}$ for water. So, there is approximately $10^{\circ} \mathrm{C}$ improvement in the cooling of a heat exchanger by the usage of silica nanofluid in place of conventional water.
The CFD analysis is performed for the same heat exchanger using the same experimental heat exchanger design specifications. The CFD analysis results are shown in Table 5. We get the outlet temperature of the hot tube as $354.03 \mathrm{~K}$ and the cold tube as $313.18 \mathrm{~K}$. The temperature results are obtained for course, medium and fine meshing of the heat exchanger. The cold outlet temperatures for course, medium and fine mesh are $314.25 \mathrm{~K}, 312.3 \mathrm{~K}$ and $311.21 \mathrm{~K}$ respectively. While the hot outlet temperatures for course, medium and fine mesh are $348.33 \mathrm{~K}, 349.99 \mathrm{~K}$ and $350.02 \mathrm{~K}$ respectively.

Figure 7 represents that the comparison between the results obtained through experimental results and the CFD results of both the cold fluid and hot fluid. The mesh generated for the heat exchanger is imported into ANSYS Fluent to perform the post processing operation. After importing the mesh, the properties of materials 


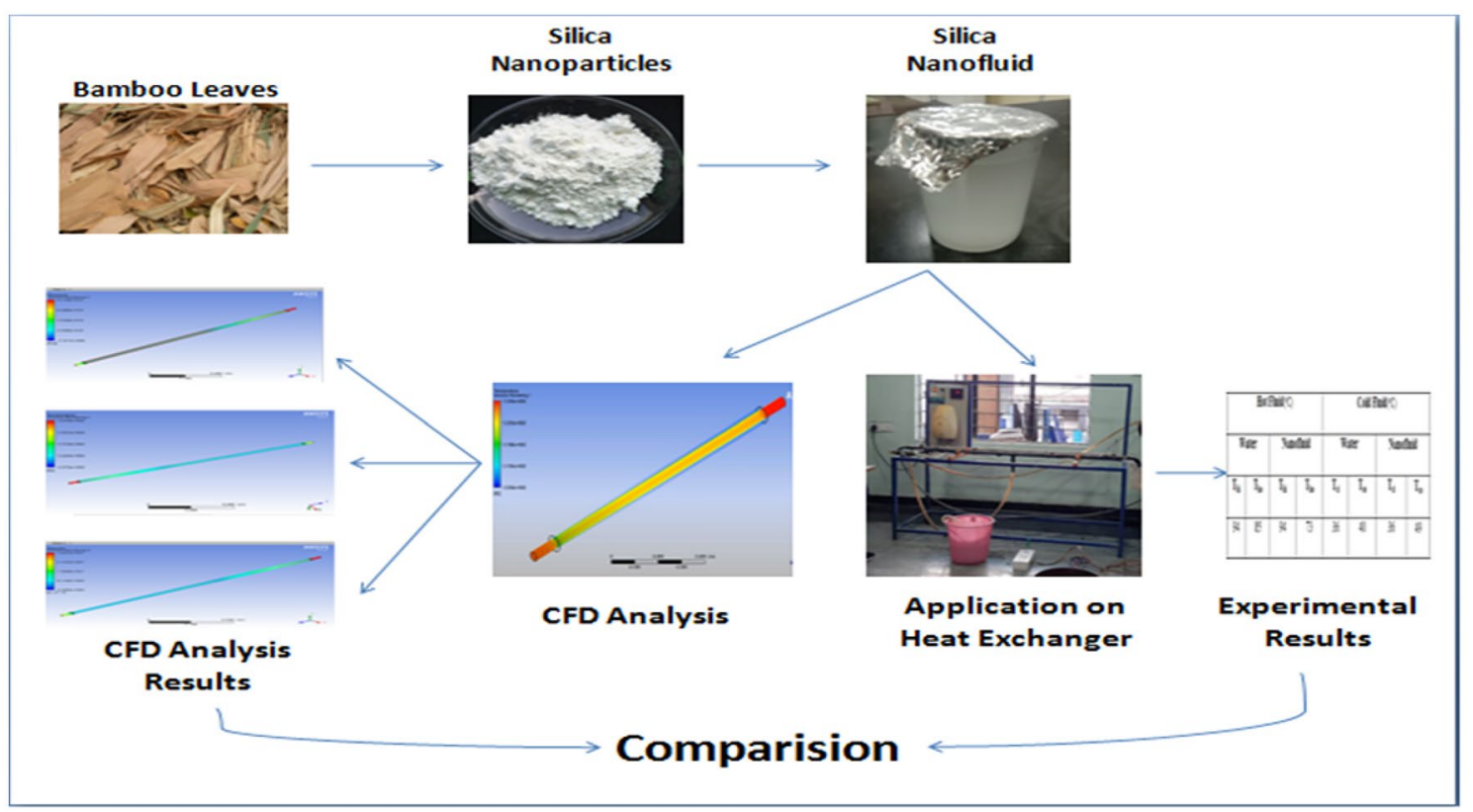

Fig. 6 Schematic figure of the investigation

Table 4 Experimental results

\begin{tabular}{|c|c|c|c|c|c|c|c|}
\hline \multicolumn{4}{|c|}{ Hot fluid $\left({ }^{\circ} \mathrm{C}\right)$} & \multicolumn{4}{|c|}{ Cold fluid $\left({ }^{\circ} \mathrm{C}\right)$} \\
\hline \multicolumn{2}{|c|}{ Water } & \multicolumn{2}{|c|}{ Nanofluid } & \multicolumn{2}{|c|}{ Water } & \multicolumn{2}{|c|}{ Nanofluid } \\
\hline $\mathrm{T}_{\mathrm{hi}}$ & $\mathrm{T}_{\text {ho }}$ & $\mathrm{T}_{\mathrm{hi}}$ & $T_{\text {ho }}$ & $\mathrm{T}_{\mathrm{ci}}$ & $\mathrm{T}_{\text {co }}$ & $\mathrm{T}_{\mathrm{ci}}$ & $\mathrm{T}_{\text {co }}$ \\
\hline 94 & 85 & 94 & 73 & 36 & 40 & 36 & 49 \\
\hline
\end{tabular}

Table 5 CFD result of experimental apparatus

\begin{tabular}{|c|c|c|c|}
\hline \multicolumn{2}{|c|}{$\begin{array}{l}\text { Temperature of } \\
\text { cold fluid (K) }\end{array}$} & \multicolumn{2}{|c|}{$\begin{array}{l}\text { Temperature } \\
\text { of hot fluid (K) }\end{array}$} \\
\hline nlet & Outlet & Inlet & Outlet \\
\hline 309 & 313.18 & 367 & 354 \\
\hline
\end{tabular}

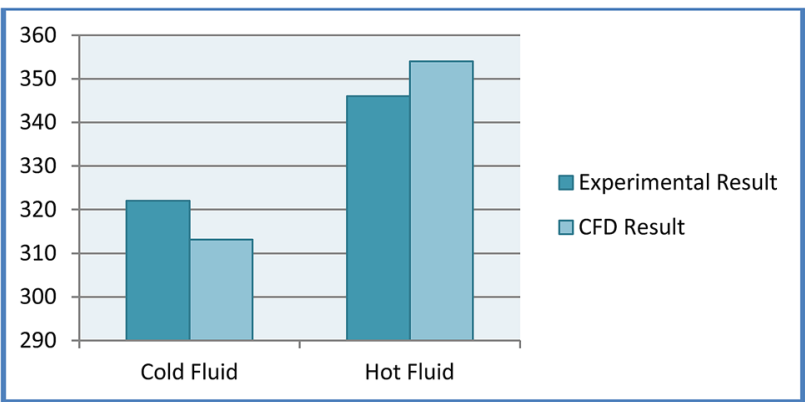

Fig. 7 Comparison of experiment and CFD results and the fluids used in the outer and inner pipe are defined along with the other boundary conditions. The results are obtained after performing number of iterations. Figures 8,9 and 10 show the temperature, pressure and velocity distributions of the heat exchanger respectively.

Realizable K-epsilon (k- $\varepsilon$ ) turbulence model was used in the CFD analysis with enhamced wall treatment. The TKE, TDR and Energy Prandtl number values are 1, 1.2 and 0.85 respectively. In Fig. 8 it can be clearly observed that the temperature of the inner pipe gets reduced as the fluid travels from inlet to the outlet. Figure 11 shows the residual plot which gives accuracy of the solution. It also helps in determining the convergence of the solution. The animated flow of both the hot and the cold fluid is shown in Fig. 12.

Figures 13 and 14 represent the face plane representation of the inlet and outlets of both the inner and the outer pipes of the double pipe heat exchanger. Figure 13 shows the cold inlet and hot outlet temperature contours while Fig. 14 shows the hot inlet and cold outlet contours of the temperatures. A clear variation in the 
Fig. 8 Temperature distribution of experimental apparatus

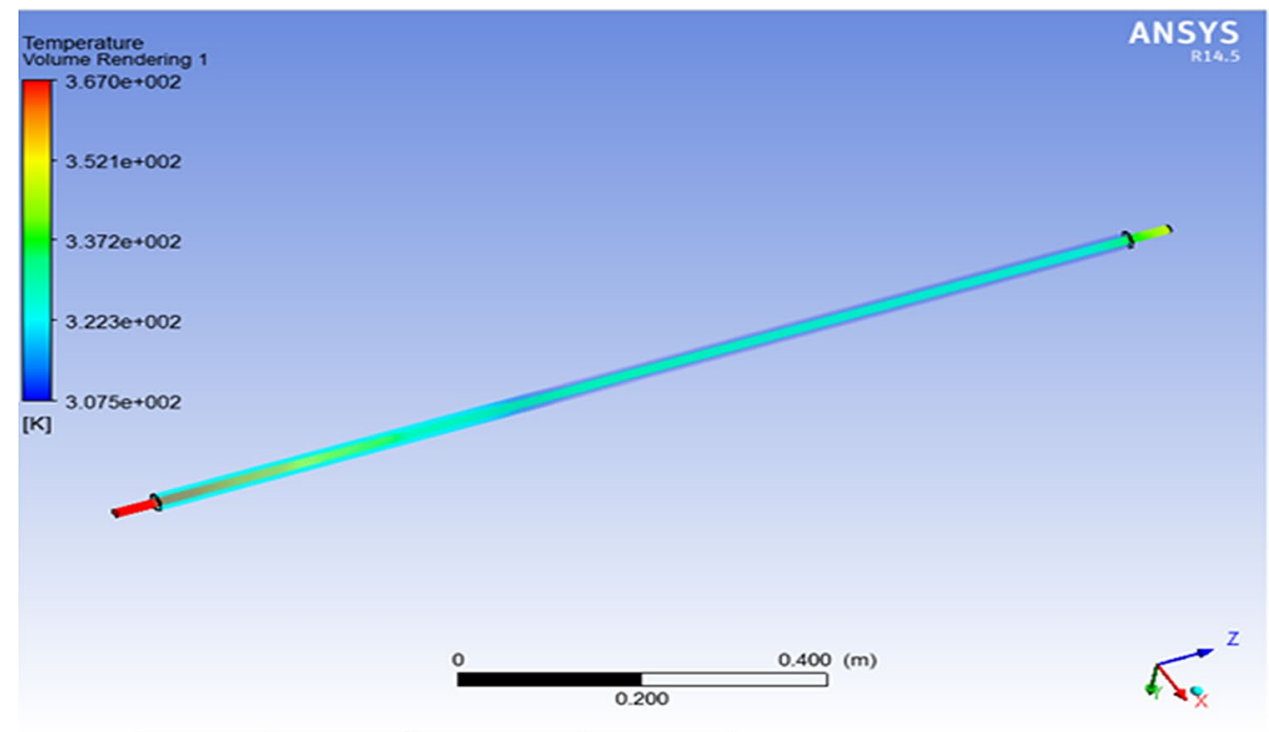

Fig. 9 Pressure distribution of experimental apparatus

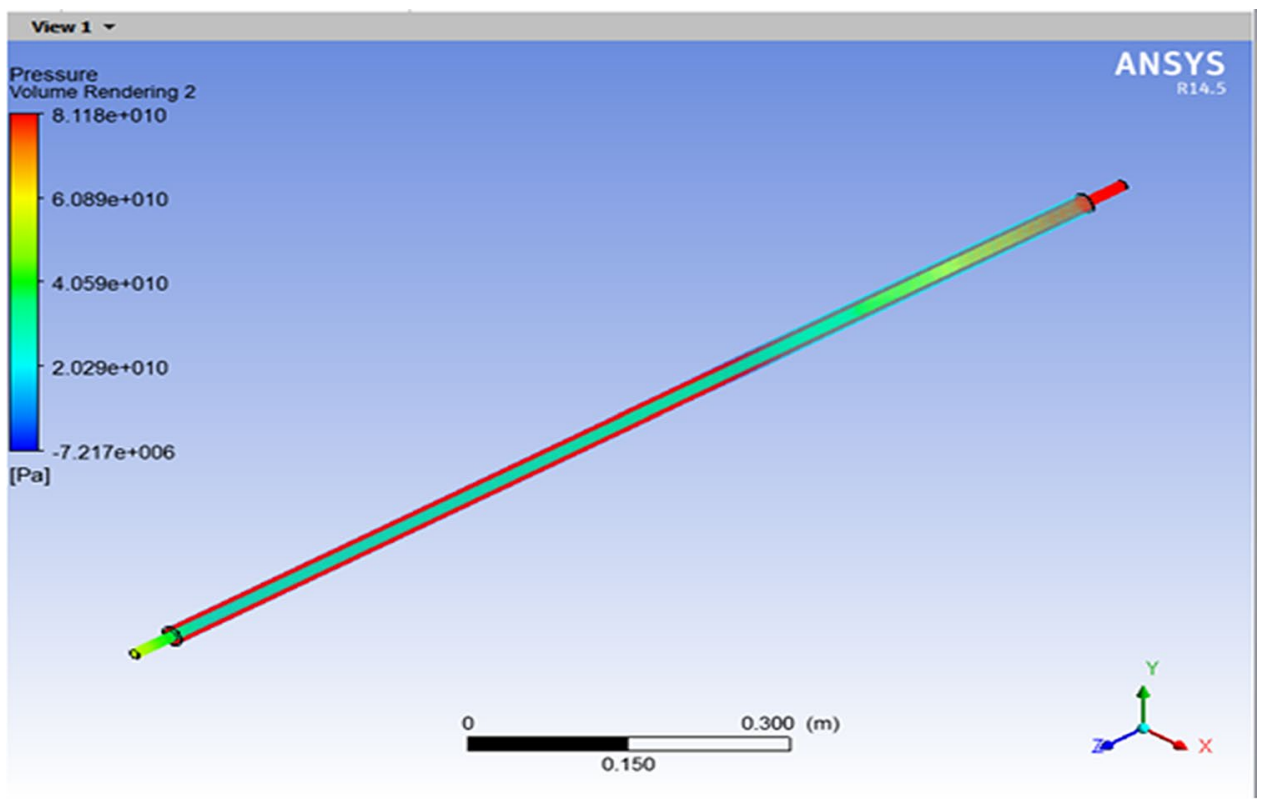


Fig. 10 Velocity distribution of experimental apparatus

Fig. 11 Residual values plot

\section{SN Applied Sciences}

a SPRINGer Nature journal
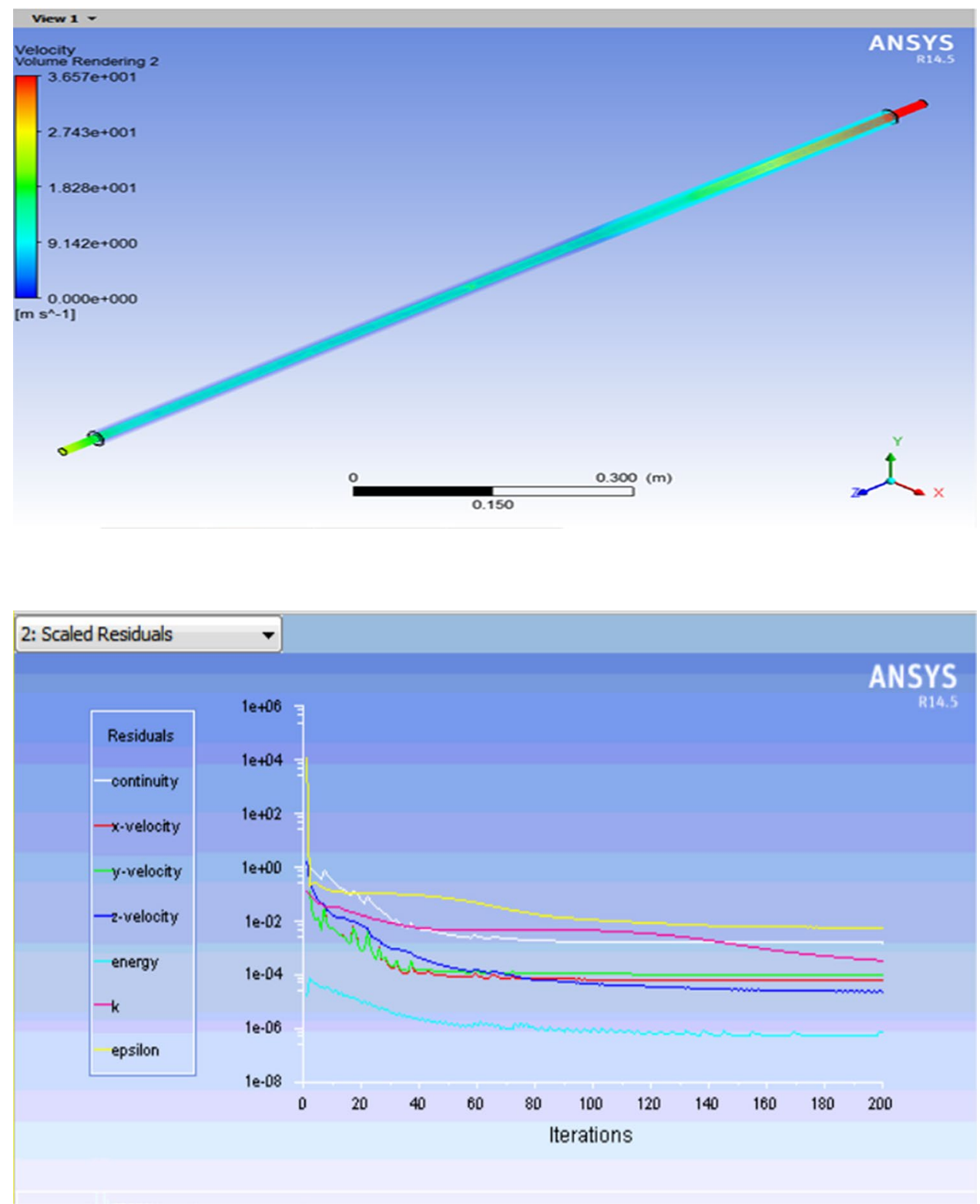
Fig. 12 Animation representing hot and cold fluid flow

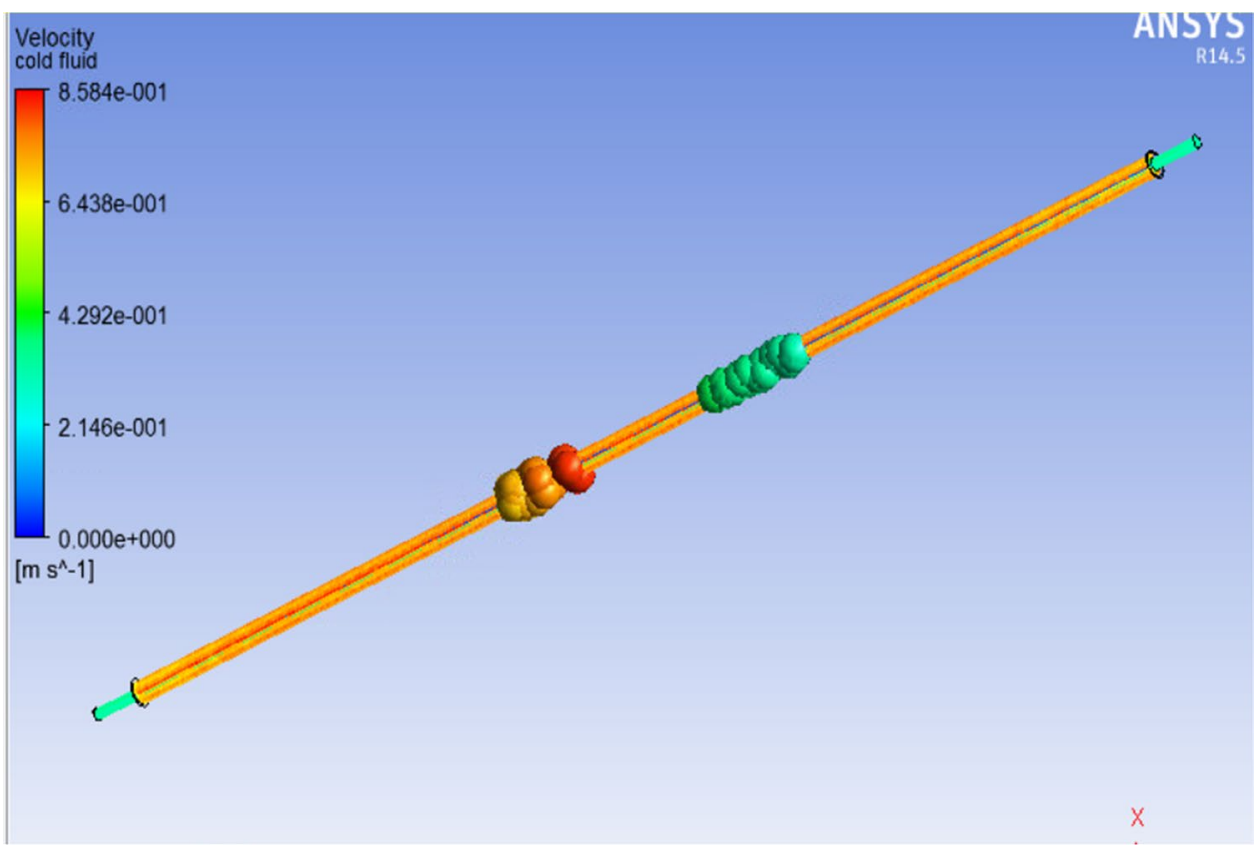

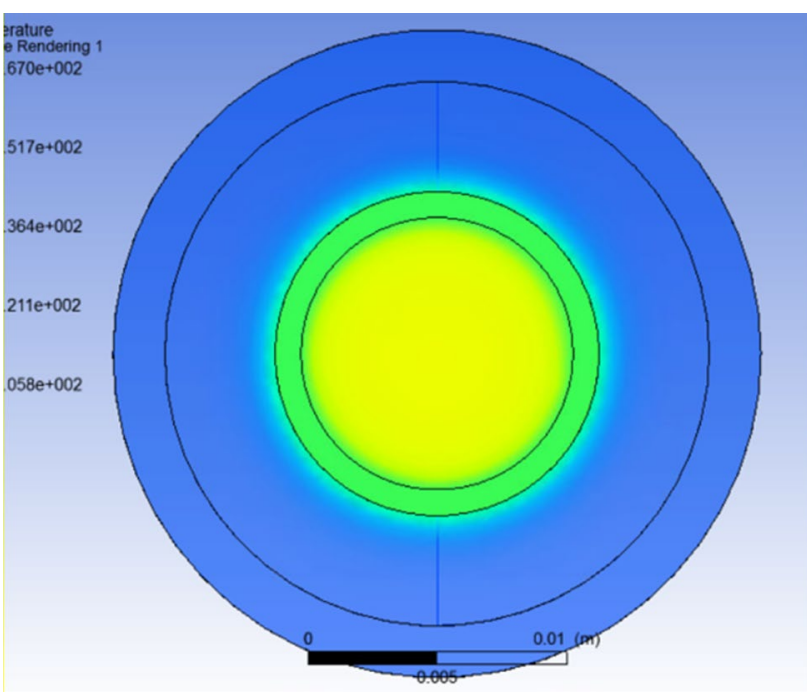

Fig. 13 Cold inlet and hot outlet of heat exchanger

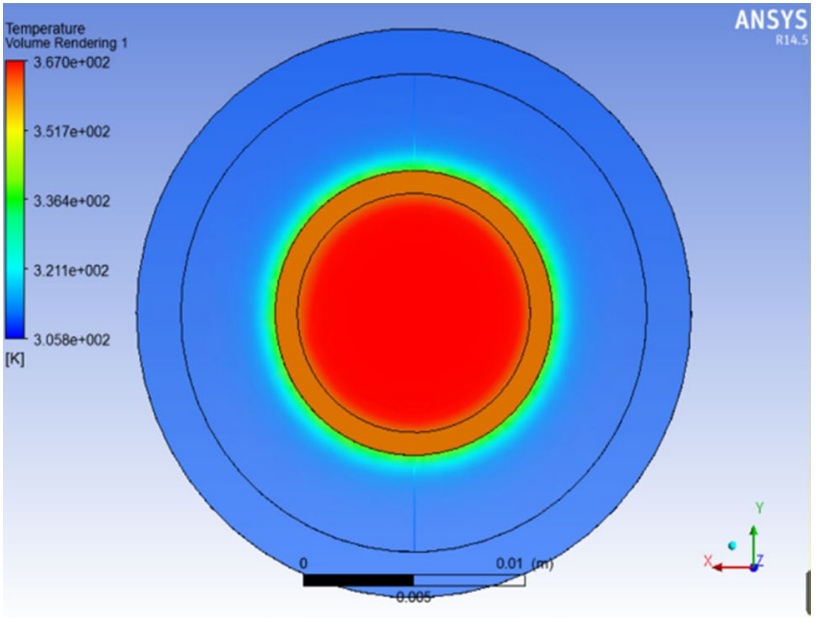

Fig. 14 Hot inlet and cold outlet of heat exchanger 
temperature of the hot fluid can be observed from both the figures.

\section{Conclusion}

In the present study, silica nanofluid prepared by green synthesis process was used in place of conventional fluid. The comparision of the heat transfer was done when both silica nano fluid and water were used to the usage of only water as the inner and outer fluids. The results state that the thermal efficiency was increased by $10^{\circ} \mathrm{C}$, when silica nano fluid was used. The validation for the results is obtained through the experimentation and the CFD analysis. The usage of nano fluids results in the improvement of heat transmission which in turn enhances cooling.

\section{Compliance with ethical standards}

Conflict of Interest The authors declare that they have no competing interests

\section{References}

1. Choi SUS (1995) Enhancing thermal conductivity of fluids with nanoparticle. ASME FED 231. p 99

2. Hamilton RL, Crosser O (1962) Thermal conductivity of heterogeneous two component systems. Ind Eng Chem Fund 1(3):187-191

3. Sai Bhargava Reddy M, Kailasa S, Geeta Rani B et al (2019) $\mathrm{MgO} @ \mathrm{CeO}_{2}$ chemiresistive flexible sensor for room temperature LPG detection. J Mater Sci Mater Electron 30:17295-17302

4. Reddy MSB, Kailasa $\mathrm{S}$, Geeta Rani $\mathrm{B}$ et al (2020) $\mathrm{CeO}_{2}$ nanohexagons decorated $\mathrm{rGO} / \mathrm{CNT}$ heterostructure for high-performance LPG sensing. SN Appl Sci 2:402

5. Kailasa $\mathrm{S}$ et al (2020) NiO nanoparticles-decorated conductive polyaniline nanosheets for amperometric glucose biosensor. Mater Chem Phys 242:122524

6. Munindra P, Sai Bhargava Reddy M, Geeta Rani B et al (2020) A high-performance low-temperature LPG detection by $\mathrm{MgFe}_{2} \mathrm{O}_{4} / \mathrm{BiVO}_{4}$ chemiresistive sensor. J Mater Sci Mater Electron 31:2370-2377

7. Sai Bhargava Reddy M, Geeta Rani B, Kailasa S et al (2020) $\mathrm{Sm}_{2} \mathrm{O}_{3}$ rice-like nanorods decorated on $\mathrm{rGO}$ flexible resistive sensor for room temperature LPG detection. Mater Sci Eng B 262:114757

8. Sheikholeslami M et al (2020) Performance of solar collector with turbulator involving nanomaterial turbulent regime. Renew Energy 163:1222-1237

9. Sheikholeslami M, Farshad SA (2020) Nanoparticle transportation inside a tube with quad-channel tapes involving solar radiation. Powder Technol 378:145-159
10. Pak BC, Cho YI (1998) Hydrodynamic and heat transfer study of dispersed fluids with submicron metallic oxide particles. Exp Heat Transfer 11:151

11. Duangthongsuk W, Wongwises S (2009) An experimental study on the heat transfer performance and pressure drop of $\mathrm{TiO}_{2}$-water nanofluids flowing under a turbulent flow regime. Int J Heat Mass Transfer. https://doi.org/10.1016/J.IJHEATMASS TRANSFER.2009.09.024

12. Godson L, Raja B, Mohan Lal D, Wongwises S (2010) Enhancement of heat transfer using nanofluids-an overview. Renew Sustain Energy Rev 14:629-641

13. Kakac S, Pramuanjaroenkij A (2009) Review of convective heat transfer enhancement with nanofluids. Int J Heat Mass Transfer 52:3187-3196

14. Wang XQ, Mujumdar AS (2008) A review on nanofluids - Part II: experiments and applications. Braz J Chem Eng 25(4):631-648

15. Tsai CY, Chien HT, Ding PP, Chan B, Luh TY, Chen PH (2004) Effect of structural character of gold nanoparticles in nanofluid on heat pipe thermal performance. Mater Lett 58:1461

16. Wen D, Ding Y (2004) Experimental investigation into convective heat transfer of nanofluids at the entrance region under laminar flow conditions. Int J Heat Mass Transfer 47:5181

17. Yang Y, Zhang ZG, Grulke EA, Anderson WB, Wu G (2005) Heat transfer properties of nanoparticle-in-fluid dispersions (nanofluids) in laminar flow. Int J Heat Mass Transfer 48(6)

18. Ding $Y$, Alias $H$, Wen D, Williams RA (2005) Heat transfer of aqueous suspensions of carbon nanotubes (CNT nanofluids). Int J Heat Mass Transfer 49(1-2):240

19. Khedkar RS, Sonawane SS, Wasewar KL (2012) Influence of $\mathrm{CuO}$ nanoparticles in enhancing the thermal conductivity of water and mono ethylene glycol based nanofluids. Int Commun Heat Mass Transfer 39:665-669

20. Yu W, Xie H, Wang X, Wang X (2011) Significant thermal conductivity enhancement for nanofluids containing graphene nanosheets. Phys Lett A 375(10):1323-1328

21. Harris SZ, Etemad SG, Nasr Esfahany M (2006) Experimental investigation of oxide nanofluids laminar flow convective heat transfer. Int Commun Heat Mass Transfer 33(4):529-535

22. Sharma $P$ et al (2010) Enhancement of thermal conductivity of ethylene glycol based silver nanofluids. Powder Technol 208(1):17-19

23. Pendyala R, Wong YS, Ilyas SU (2015) CFD simulations of natural convection heat transfer in enclosures with varying aspect ratios. Chem Eng Trans 45:793-798

24. Bhanuchandrarao $D$, Ashok Chakravarthy $M$, Krishna $Y$, Subba Rao VV (2013) CFD analysis and performance of parallel and counter flow in concentric tube heat exchangers. Int J Eng Res Technol 2(11)

25. Kamyar A, Saidur R, Hasanuzzaman M (2012) Application of computational fluid dynamics (CFD) for nanofluids. Int J Heat Mass Transfer 55:4104-4115

26. Rangaraj S, Venkatachalam R (2017) A lucrative processing of bamboo leaf biomass to synthesize biocompatible amorphous silica nanoparticles of biomedical importance. Appl Nanosci 7:145-153

27. Sai Bhargava Reddy M, Jayarambabu N, Kiran Kumar Reddy R, Kailasa S, Venkateswara Rao K (2019) Study of acoustic and thermodynamic factors of synthesized $\mathrm{ZnO}$-water nanofluid by ultrasonic technique. Mater Today Proc. https://doi. org/10.1016/j.matpr.2019.04.200

Publisher's Note Springer Nature remains neutral with regard to jurisdictional claims in published maps and institutional affiliations. 